there is a named team supporting them, facilitated increased knowledge of all current patients, and supported the team as patients are reviewed by other CNS colleagues, reducing the risk of assessment/treatment variation.

\section{P-226 REDESIGNING A COMMUNITY PALLIATIVE CARE SERVICE FIT FOR THE FUTURE}

Helen Reeves, Katie Taroni. St Giles Hospice, Whittington, UK

\subsection{6/bmispcare-2017-hospice.251}

Background In 2016 St Giles Hospice undertook a review of its community palliative care services to ensure the service would be fit for the future. This entailed a review of team caseloads and how and who they were managed by.

Aims Community palliative care services have been historically very linear in their approach, mainly compromising of clinical nurse specialists. The aim of the review was to identify the numbers and complexities of patients on the caseloads and produce recommendations for how caseloads could be managed more efficiently ensuring patients were seen by the right professional or person at the right time.

Methods We reviewed the number of patients on the caseloads (approximately 550 at any one time) and identified if their needs were stable, deteriorating or unstable. We then reviewed which nurse was allocated to patients and identified whether patients were moved through the team or whether they stayed with one nurse throughout their journey.

Results After reviewing the case loads it was realised our structure needed adjusting. As a result, we now have a tiered approach to our community team. Our staff nurses will see the most stable patients or patients at the beginning of their journey with us, clinical nurse specialists will see patients whose condition is changing and our advanced CNSs will see our most complex patients. This means that patients are seen by the right person at the right time via step up or step down approach and has enabled us to see 1300 extra patients in 2016-2017.

Conclusion Service review continues and as a result we will be adding lead advanced nurse practitioners to the team and community care volunteers as we continue to evolve our service to ensure we can be responsive to the needs of the communities we serve.

\section{P-227 TYNEDALE HOSPICE AT HOME: COMING OF AGE!}

Sandie Faircloth, Sylvia Ritson. Tynedale Hospice at Home, Hexham, UK

10.1136/bmispcare-2017-hospice.252

Background 21 years ago our hospice evolved to facilitate local residents to be able to die in their home wherever possible. However, as the current professional landscape is evolving amid a plethora of regulation, a new initiative is taking control of its metamorphosis from an altruistic venture into a pioneering professional organisation committed not only to the safe delivery of high quality care fit for purpose in the 21 st century, but as an exemplar of innovation and gold standard bespoke person-centred care.

Aims To ensure that the service not only complies with CQC standards but seeks to work towards 'Outstanding' by enhancing patient centred care
To ensure that as a charitable organisation the care services provide best value for money in a clear transparent patient focused evidence-based service.

Method The organisation took the unique decision to employ two senior nurses explicitly to drive forward this ambition. They are tasked with two broad key drivers: training and development; quality improvement. Their roles are designed to be both interactive and most crucially, interdependent. The methods employed include:

- developing standards of practice

- deficits identified

- organisation specific training and development

- developing a training and development matrix

- developing quality framework and model

- developing standards of practice

- audit based on agreed standards

- develop an induction package for new staff

- set up appraisal framework.

Results Currently the senior nurses have only been in post for 12 weeks and already there have been significant positive developments. Work is in progress in all areas and the two key frameworks will act as a single platform to analyse, plan and measure future achievements.

Conclusion This is early days in the development of this unique partnership, however, the positivity so far has been encouraging and supported by all staff, volunteers and trustees.

\section{P-228 WIDENING INVOLVEMENT OF SERVICE USERS, CARERS AND CITIZENS IN PALLIATIVE CARE ON ISLAND OF IRELAND}

Brendan O'Hara, Karen Charnley. All Ireland Institute of Hospice and Palliative Care, Dublin, Ireland

\subsection{6/bmispcare-2017-hospice.253}

Background The meaningful involvement of people receiving palliative care (service users), carers and the wider community is essential to informing palliative care education, research, policy and practice.

A group was established on the island of Ireland in 2013 for this involvement. By 2016, as this group had come to the end of its membership term, a significant project was undertaken to refresh membership.

Aim(s) The aim was to renew and refresh group membership, fostering diversity of membership and ensuring that involvement remained worthwhile, and to increase the remit of the group's involvement in health structures in both jurisdictions on the island. Consideration was also given to a range of flexible methods of involvement wider than the original concept.

Method A recruitment drive was launched by the recruiting organisation in July 2016. This was supported by a suite of information on the organisation's website - promotional flyer, video, information leaflet, guidance for applicants and an expression of interest form. The opportunity was promoted through other networks; use of the flyer, email, social media and a press release.

Results More than 60 people asked to find out about the opportunity and 45 expressions of interest forms were received. A small number of applications were not progressed when involvement was clarified. An opportunity to renew membership was extended to current members. Invitations 